\title{
Long-Tail Distributions And Total Returns On Risk-Based Investment Products
}

Albert E. DePrince, Jr., Middle Tennessee State University, USA A. Eugene DePrince III, Florida State University, USA

\begin{abstract}
Use of target date funds (TDFs) in retirement plans increased in popularity following the 20072008 financial crisis. However, some argued that TDFs do not provide an acceptable level of protection against market downturns and long-tail events. This study assesses the ability of TDFs to deal with long-tail events. It builds a system of equations for seven asset classes that are used to build four hypothetical TDFs, and compares simulated total returns for four hypothetical TDFs over a 50-year horizon, where the stochastic terms for each of the underlying asset classes is based on the normal distribution and a long-tail distributions (the Laplace distribution). Simulations are repeated 2000 times. Total returns for four TDFs are calculated over nonoverlapping 1-, 2-3-, and 5-year horizons over the 50-year span for the 2000 simulations. Results show that about half the time the risk measure for the long-tail distribution are wider than the normal, and about half the time the opposite holds. It seems that the processes of asset diversification along with calculating returns over horizons of at least one year mitigates effects of long-tail characteristics. Even so, results do not bode well for those nearing retirement. Negative returns over 1- and 2-year investment horizons are possible 17\% of the time for a conservative allocation over a 50-year period.
\end{abstract}

Keywords: Long-Tail Distributions; Risk-Based Investment Products; Target Date Funds (TDF), Asset Allocation

\section{INTRODUCTION}

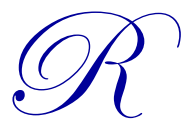

etirement plans have come under political scrutiny, in the aftermath of the 2007-2008 financial crises. Arguments were made that, at the very least, the target date retirement funds failed to provide an acceptable level of protection against the market downturn (Fleck, 2013). This was particularly obvious among funds within a short distance to expected retirement (Green, 2009) Beyond this, there is some political sympathy for the view that individuals cannot be left to the own accord with respect to retirement planning. This view is usually associated with the belief that there should be a return to defined benefit plans. A suggestion of a government run retirement plan that can supposedly provide a guaranteed real return also surfaced (Regnier, 2008).

Behind the concern over 2008 loses, stand the ongoing shift from defined benefit to defined contribution plans. As a result, an increasing number of individuals will need to manage their own retirement portfolios in the futures. Hence, the ability to weather long-tail events will be faced by an ever increasing numbers. This study assesses the ability of strategic allocation funds to provide protection against black swan events. It begins with a simple portfolio that has exposure to domestic equity, developed country equity, emerging market equity, and fixed income. Equations for each asset class are estimated and simulated over a 50-year (600 month) horizon using error terms drawn from a long-tail and normal distributions. The study's importance lies in its ability assessing the protection possible against black swan events and the tradeoff between protection and return. 
It begins with a brief review of the two broad classes of risk-based investment product and goes on to lay out the asset allocation alternatives that will serve as the risk-based portfolios in this study. The model of the total returns for each of the underlying asset classes in the risk-based portfolios is next developed. Seven board asset classes form the underlying assets in each of the risk-based portfolios and a Vector Autoregressive Model (VAR) is used to capture the inter-relationship among the total returns on the asset classes.

Next, the data sources are reported followed by the estimation results for the seven equation VAR system. The discussion them turns to the draws form the long-tail and the normal distributions for the seven asset classes. This section also contains the mechanism used to replicate the high degree of observed co-linearity among returns on the seven asset classes. The section ends with the integration of the error terms into the seven respective asset classes.

Next, a summary of the simulation results is reported. The model is simulated over a 50-year investment horizon, where the stochastic terms for each of the underlying asset classes is based on the normal distribution and the Laplace distribution, as a representative long-tail distribution. Variability of the simulate portfolio returns are calculated over the 50-year horizon ands well as progressively shorter horizons. The simulations are repeated 2000 times.

\section{RISK AND RETIREMENT SAVINGS}

Risk has received heightened focus in response to the 2008 financial crisis. However, years before the latest crisis, the collapse on Monday, October 19, 1987, exceeded any previously known one-day fall in equity prices. In hindsight, this led to the notion of "Black Swan" events which in the simplest case are observations outside known previously known outcome. Focusing on the October $19^{\text {th }}$ market crash, Bogle (2007) provides summary of the background research on Black Swans in financial markets.

As time progressed after the collapse, most researchers concluded that the usual assumption of normally distributed returns is flawed, since known history does not reflect all possible outcomes. Tails of the underlying distribution from which returns are drawn are far longer (and by implication far fatter) that the normal distribution. Because of that, it is argued that simulations based upon the normal distribution understate risk. This study seeks to quantify the degree of understatement of risk in the normal distribution.

\section{RISK-BASED INVESTMENT VEHICLES}

To deal directly with risk and asset accumulation, two broad classes of risk-based investment products have emerged in the mutual fund industry: life cycle funds which are known as target date funds (TDF) and life style funds. The risk characteristics of TDF change over time and are the focus of this study. In contrast, life style funds are funds that have set risk characteristics across time. These are both typical fund of funds, where a fund of fund is an investment company (i.e., a mutual fund) that invests in other mutual funds rather than in individual stocks.

The proportion each asset class in a TDF is automatically adjusted during the course of the fund's time horizon. The further the retirement date is in the future, the more aggressive is the asset mix. Portfolios are rebalanced ever five years, so the rebalancing gradually moves from a higher risk strategy (with high expected returns) to lower risk strategies as the investor moves toward retirement

Target date funds have a single, but compelling, advantage. They provide investors with the ability to basically put their investing activities on autopilot through the use of just one professionally fund, which is managed for them. While appealing, there are a number of issues surround TDFs. "One size fits all" approach is suspect, and the glide path (the change in the allocation across asset classes over time) differs among funds complexes. There are also wide differences in asset allocations for any given target date among asset managers. The differing asset mixes at each age among complexes may reflect different risk characteristics among asset managers. 
These funds have grown in popularity and one report shows that nearly three quarters of all plans offered TDFs in their fund line-up (Hersch, 2013). Another report shows assets at $\$ 503$ billion at year-end 2013 (Hunnicutt, 2013).

\section{PREVIOUS SIMULATION RESEARCH}

This paper is related to but differs from much of the target date simulation studies. These studies employ stochastic simulations (as does this study) but their purpose is to study the accumulation of retirement wealth given risk parameters. For example, Poterba, Rauh, Venti, and Wise (2005) exam wealth accumulation under alternative asset allocation rules. Next, Pang and Warshawsky (2009) assess the accumulation of retirement wealth where there is a trade-off between wealth accumulation and safety

Finally, under contract with the department of Labor, Brien, Cross, Dunn, Pharris, Panis (2010) use three simulation model developed by the Policy Simulation Group designed to estimate retirement plan benefits. Unlike earlier studies, these are complicated models with a variety of equations on marital status, employment income availability of plans, contributions and withdrawal rates. Beyond this brief summary, space and the purpose of this paper's research do not permit greater detail.

In contrast, this paper simply seeks to provide a sense of risk attached to alternative asset allocations using alternative distributions for the error terms in the various equations for the total returns of the various underlying asset classes. While it does not asses the ability of accumulate assets to provide a life-long benefit after retirement, it does show the high degree of risk, even in very "safe" asset allocations. Implication of this are discussed at the end of the paper.

\section{RISK ACROSS TARGET DATE FUNDS}

Measuring risk across alternative target date funds is complicated. One way of comparing risk across alternative fund families is to examine the mix between equity and bonds at set target dates. More equity would supposedly point to more risk and vice versa. A review of the 10 largest target dates suites (downloaded from various web sites) show a high of 23 fund and a low of 5 funds, with the rest distributed between the two. There is a considerable difference in the mix between equity and fixed income funds in each of the funds families.

Differences in the mix of equity and fixed-income securities reflect different risk characteristics of the glide path of the funds as the time to retirement nears. Additionally, difference between "to" and "through" retirement. TDFs will different allocations between equities and fixed-income securities over their respective glide path as well as in the years after retirement. "Through" retirement have changing weights as the individual moves through retirement versus fixed weights in the allocation for the "to" retirement TDFs. Equity funds are larger share of fund assets for the "through" retirement TDFs throughout the glide path as well at retirement compared with "to" retirement funds. This is seen in indexes prepared by S\&P illustrating this difference between the two glide path in Figure 1 below (Murphy and Scraturro). In this, the 2015 TDF would be the point where retirement income begins. Thus, on average, TDFs that go "through" retirement are built on roughly a $60 \%$ equity allocation in the early stage of retirement versus about a $30 \%$ equity allocation for TDFs that go "to" retirement.

The mix in the equity content and the fix-income content also changes as funds move through the glide path. To illustrate this, Table 1 reports the asset allocations in the S\&P TDF Index Series across the glide path of TDFs. They go from a high of $90 \%$ equity for TDF 2055 to $31 \%$ for the Retirement Income TDF. These indexes were developed as a possible alternative for benchmarking TDFs, and they did serve as input into the structure of the hypothetical TDFs used in this study. 


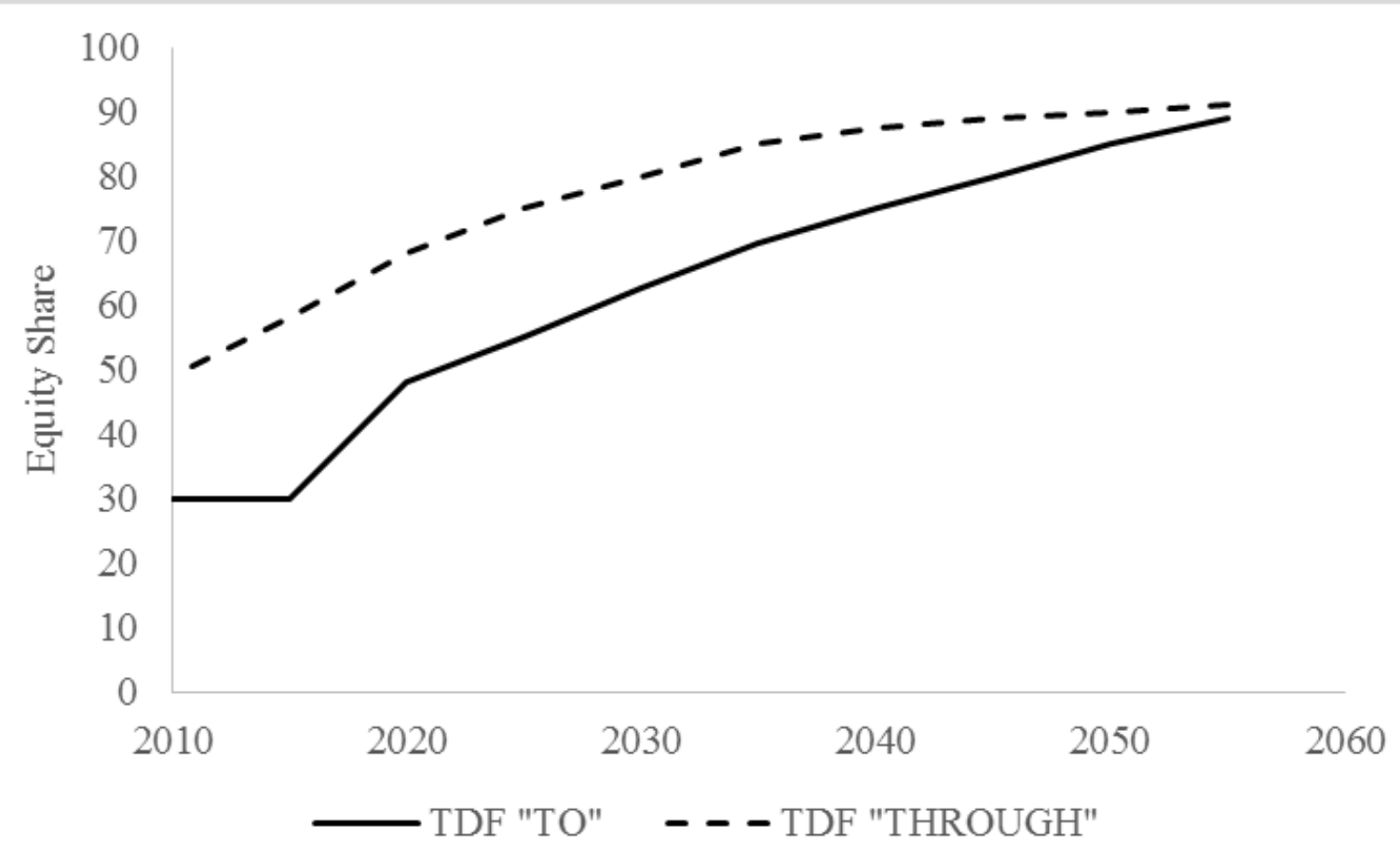

Source: Murphy and Scraturro (2012)

Figure 1: Equity Share of TDF "To" versus TDF "Through"

\section{ASSET ALLOCATION ALTERNATIVES IN THIS MODEL}

Four asset allocations schemes are considered. The baseline allocation is set at $75 \% / 25 \%$ split between equity and fixed income securities. This corresponds to roughly TDF 2030 fund based on Table 1 . Three others allocations are also considered. These are listed below.

- $\quad$ A 95\% / 5\% equity / fixed income mix which (based on Table 1) corresponds to a TDF 2055. This can also be considered an "aggressive" portfolio allocation.

- $\quad$ A 50\% / 50\% mix which corresponds to a TDF 2015 in Table 1 and could be considered a balance portfolio

- A 25\% / 75\% equity / fixed income split which corresponds to a Retirement Income Fund. This might also be considered a conservative allocation. 
Table 1: Asset Allocation (as \% of total assets) in S\&P Target Date Index Series

\begin{tabular}{|c|c|c|c|c|c|c|c|c|c|c|c|}
\hline & $\begin{array}{l}\text { Retirement } \\
\text { Income }\end{array}$ & 2010 & 2015 & 2020 & 2025 & 2030 & 2035 & 2040 & 2045 & 2050 & 2055 \\
\hline $\begin{array}{l}\text { U.S.Large } \\
\text { Cap }\end{array}$ & 16.90 & 21.70 & 25.90 & 29.50 & 32.70 & 35.80 & 37.80 & 39.50 & 40.80 & 41.80 & 42.90 \\
\hline $\begin{array}{l}\text { U.S. Mid } \\
\text { Cap }\end{array}$ & 3.90 & 5.70 & 7.40 & 8.70 & 9.90 & 11.00 & 11.70 & 12.30 & 12.70 & 12.90 & 13.10 \\
\hline $\begin{array}{l}\text { U.S. Small } \\
\text { Cap }\end{array}$ & 1.30 & 2.00 & 2.70 & 3.20 & 3.70 & 4.20 & 4.50 & 4.80 & 5.10 & 5.30 & 5.50 \\
\hline $\begin{array}{l}\text { Intern'l } \\
\text { Equities }\end{array}$ & 7.40 & 10.10 & 12.60 & 14.80 & 16.80 & 18.80 & 20.30 & 21.60 & 22.70 & 23.80 & 24.90 \\
\hline $\begin{array}{l}\text { Emerging } \\
\text { Markets }\end{array}$ & 1.30 & 1.80 & 2.40 & 2.80 & 3.30 & 3.70 & 4.10 & 4.40 & 4.70 & 5.00 & 5.20 \\
\hline U.S. REITs & - & - & - & 1.00 & 1.20 & 1.30 & 1.30 & 1.30 & 1.30 & 1.30 & 1.20 \\
\hline $\begin{array}{l}\text { Fixed- } \\
\text { Income }\end{array}$ & 42.20 & 37.00 & 32.10 & 27.20 & 22.90 & 19.00 & 15.20 & 11.80 & 8.80 & 6.40 & 4.70 \\
\hline $\begin{array}{l}\text { Cash } \\
\text { Equivalents }\end{array}$ & 15.10 & 12.20 & 9.60 & 7.40 & 5.60 & 4.30 & 3.30 & 2.70 & 2.50 & 2.50 & 2.50 \\
\hline TIPS & 9.30 & 6.90 & 4.90 & 3.10 & 1.70 & - & - & - & - & - & - \\
\hline $\begin{array}{l}\text { High-Yield } \\
\text { Corporates }\end{array}$ & 2.60 & 2.50 & 2.40 & 2.30 & 2.10 & 2.00 & 1.80 & 1.60 & 1.40 & 1.10 & - \\
\hline Equities & 30.80 & 41.30 & 51.00 & 60.00 & 67.60 & 74.80 & 79.70 & 83.90 & 87.30 & 90.10 & 92.80 \\
\hline $\begin{array}{l}\text { Fixed- } \\
\text { Income }\end{array}$ & 69.20 & 58.60 & 49.00 & 40.00 & 32.30 & 25.30 & 20.30 & 16.10 & 12.70 & 10.00 & 7.20 \\
\hline
\end{tabular}

Source: S\&P Dow Jones Indices, 2012

\section{RESTRICTIVE ASSUMPTION} below:

Before developing the model, several restrictive assumptions need to be noted. These are summarized

- There is a single cash investment at the start of the simulation period. There are no periodic investments as would exist in a typical retirement plan. While may seem an unrealistic assumption, it does simplify the calculations. More importantly, it allows for a focus on the effects of the error terms on total returns without corrupting results with periodic cash infusions.

- $\quad$ Since the weights are constant period to period for each of the four TDFs, it assumes that portfolios are rebalanced monthly.

- $\quad$ The glide path does not change over the course of the simulation horizon. This contrasts with the more typical practice of altering the weights according to an optimization strategy, such as mean-variance optimization or a value at risk optimization. While a step back from more realistic portfolio management schemes, this restriction is necessary for this to resemble a controlled experiment.

- No new products are introduced over the simulation horizon. As with the previous assumption, this simplifies calculations, but more importantly is a necessary assumption for this to resemble a controlled experiment

- The distributions of the errors in each of the seven functions are assumed to be symmetric. There is no skewness toward either downside or upside errors

- $\quad$ There is no structural change over the 50-year horizon.

\section{THE MODEL}

The model begins with the total return of the seven asset classes. The total returns of the seven asset classes are linked together through a seven equation VAR system denoted by:

$T R_{t, j}=\beta_{j}+\beta_{1, j} x T R_{j, t-1}+\ldots+\beta_{n, j} x T R_{j, t-n}+v_{t, j}$ 
Where
$\mathrm{j}=1$
IWB -- shares ETF that tracks the Russell 1000 Index (large-cap U.S. Equity index)
$\mathrm{j}=2$
$\mathrm{j}=3$
IWR - shares ETF that tracks the Russell Mid Cap Index (mid-cap U.S. Equity index)
$\mathrm{j}=4$
IWM - shares ETF that tracks the Russell 2000 Index (small-cap U.S. equity index)
$\mathrm{j}=5$
EFA - shares ETF that tracks the MCSI EAFE Index ${ }^{1}$
$\mathrm{j}=6$
EEM - iShares ETF that tracks the MCSI EM Index ${ }^{2}$
$\mathrm{j}=7$
AGG - iShares ETF that tracks the Barclays Broad Aggregate Bond Index
SHV - iShares ETF that tracks the Barclays Short Duration Bond Index.

\section{THE DATA}

As model in the model layout above, iShares Exchange Traded Funds (EFTs) are used. These are produced by Blackrock, and are net of management fees. The sample period is dictated by data availability and begins on January 2, 2007 and ends on December 31, 2012. Essentially, the sample period is as long as the shortest data span for iShares used in this study.

Total returns are generated for each of the iShares ETFs by first calculating the capital gains yield $\left(\right.$ yield $\left._{C G, j, t}\right)$ and the dividend yield $\left(\right.$ yield $\left._{D I V, j, t}\right)$ from the month-end data extracted from the Bloomberg Data System as shown below:

$$
\text { yield }_{C G, j, t}=\frac{P_{j, t}}{P_{j, t-1}} \quad \text { and } \quad \text { yield }_{D I V, j, t}=\frac{D_{j, t}}{P_{j, t-1}}
$$

The total returns $\left(T R_{j, t}\right)$ for each of the $j$ ETFs becomes

$$
T R_{j, t}=\left(1+\text { yield }_{C G, j, t}\right) \times\left(1+\text { yield }_{D I V, j, t}\right)
$$

\section{STATIONARITY}

The usual Augmented Dickey-Fuller tests for stationarity were conducted. The tests showed that the individual total returns for each of the seven indices were stationary with virtual certainty. In the interest of full disclosure, co-integration tests were also conducted, and multiple co-integrating equations among the four total return series were found. A co-integration model with an error correction mechanism was estimated. However, out of sample simulations similar to those reported below produced results that were generally implausible. Thus, the choice of VAR is based on (1) stationarity of the series and (2) implausible results using co-integration with error correction.

\section{VAR ESTIMATION RESULTS}

Estimation results are reported in Table 2. Various lags were considered and tests for the appropriate lag were inconclusive. Thus, for simplicity two lags were used. While some may see this as arbitrary, adding lags had no net effect on to model and added to its complexity.

\footnotetext{
${ }^{1}$ The MSCI EAFE Index (Europe, Australasia, Far East) is a free float-adjusted market capitalization index designed to measure the equity market performance of developed markets, excluding the US \& Canada. It consists of the following 22 developed market country indices: Australia, Austria, Belgium, Denmark, Finland, France, Germany, Greece, Hong Kong, Ireland, Israel, Italy, Japan, the Netherlands, New Zealand, Norway, Portugal, Singapore, Spain, Sweden, Switzerland, and the United Kingdom. (Source: http://www.msci.com/products/indices/tools/index.html\#EAFE).

${ }^{2}$ The MSCI Emerging Markets Index is a free float-adjusted market capitalization index and consists of the following 21 emerging market country indexes: Brazil, Chile, China, Colombia, Czech Republic, Egypt, Hungary, India, Indonesia, Korea, Malaysia, Mexico, Morocco, Peru, Philippines, Poland, Russia, South Africa, Taiwan, Thailand, and Turkey. (Source: http://www.msci.com/products/indices/tools/index.html\#DM)
} 
Explanatory power of each function is modest at best. This finding should not be surprising, since most of the relation among total returns is contemporaneous and not among the lagged returns. Nonetheless, the $\mathrm{F}$ test for the null hypothesis that all coefficients were equal to zero was rejected at least at the five percent level of confidence for IWB, IWR, IWM, EM and SHV, while it was rejected at the eight percent level for EFA. Only AGG failed the significance test at any reasonable level of confidence.

Diagnostics of the residuals showed a high degree of contemporaneous correlation among the residuals of the seven equations. This is consistent with the usual high contemporaneous relationship among total returns, which is ignored in VAR models. This contemporaneous relationship among the error terms of the seven functions is taken into account in construction of the simulated error terms used in the simulations, a process described in the next section.

\section{THE SET-UP OF THE PORTFOLIO SIMULATIONS}

As noted earlier, two alternative distributions are consideration for the random draws of the error terms in the VAR system: the normal and the Laplace. ${ }^{3}$ Histograms of these distributions are illustrated in Figure 2 below for a mean of zero and a standard deviation of 1.0. As can be seen, the Laplace has a sharper peak and a longer-tail, in both directions, compared with the normal distribution

For each of these distributions, 2000 draws of 600 observations on seven error terms were made. This corresponds to a 50-year lifetime working horizon. Next, draws for each of the asset classes were combined with a common error term to reflect the high collinearly among total returns. This was done for both of the distributions. The following relationships were used, where $\mathrm{w}_{0}$ is the common thread among the six of the seven assets classes. It was assumed that the short-duration bond (a proxy for money market funds) is independent from the other asset classes.

$\begin{array}{ll}\text { U_iwb } & =0.85^{*} \mathrm{w} 0+.15^{*} \mathrm{w} 1 \\ \text { U_iwr } & =0.80 * \mathrm{w} 0+.20 * \mathrm{w} 2 \\ \text { U_iwm } & =0.75^{*} \mathrm{w} 0+.25^{*} \mathrm{w} 3 \\ \text { U_efa } & =0.70 * \mathrm{w} 0+.30^{*} \mathrm{w} 4 \\ \text { U_eem } & =0.50^{*} \mathrm{w} 0+.5 * \mathrm{w} 5 \\ \text { U_agg } & =0.15^{*} \mathrm{w} 0+.85^{*} \mathrm{w} 6 \\ \text { U_shv } & =\mathrm{w} 7\end{array}$

${ }^{3}$ Summarized here is the process used to generate the data from the Laplace and normal distributions. A random number, $\mathrm{x}$, that is drawn from a Laplace distribution can be obtained from another random number, a, as $x=-1 / \operatorname{sqrt}(2) \operatorname{sign}(a) \ln (1-2|\mathrm{a}|)$,

where a must be drawn from a uniform distribution between $-1 / 2$ and $1 / 2$.

A random number drawn from a Normal distribution can be obtained from two random numbers, a and $b$, as $\mathrm{x}=\operatorname{sqrt}(-2 \ln (\mathrm{a})) \cos (2 * \mathrm{pi} * \mathrm{~b})$, where $\mathrm{a}$ and $\mathrm{b}$ are both drawn from a uniform distribution between 0 and 1 . In both cases, the variance in the Laplace and Normal distributions is unity. Random variables with a uniform distribution were obtained from the rand() function of the $\mathrm{C}$ standard library. 
Table 2: Estimation Results

\begin{tabular}{|c|c|c|c|c|c|c|c|}
\hline \multicolumn{8}{|c|}{ (Sample Period: March 2007 - December 2012) } \\
\hline & $\begin{array}{c}\text { Russell } \\
1000\end{array}$ & $\begin{array}{l}\text { Russell } \\
\text { Mid-Cap }\end{array}$ & $\begin{array}{l}\text { Russel } \\
12000\end{array}$ & EAFE & $\begin{array}{c}\text { Emerging } \\
\text { Market }\end{array}$ & $\begin{array}{c}\text { Barclay Broad } \\
\text { Aggregate Bond }\end{array}$ & $\begin{array}{c}\text { Barclay Short } \\
\text { Duration Bond }\end{array}$ \\
\hline & IWB & IWR & IWM & EFA & EEM & AGG & SHV \\
\hline $\operatorname{IWB}(-1)$ & 0.753 & 0.868 & 1.180 & -0.102 & 0.231 & -0.172 & 0.010 \\
\hline T-statistics & 1.057 & 1.101 & 1.363 & -0.110 & 0.206 & -0.948 & 0.716 \\
\hline IWB(-2) & -0.802 & -1.188 & -1.349 & -0.404 & -0.657 & 0.184 & -0.001 \\
\hline T-statistics & -1.171 & -1.567 & -1.621 & -0.451 & -0.609 & 1.055 & -0.096 \\
\hline IWR(-1) & 0.974 & 1.222 & 1.341 & 1.975 & 2.489 & 0.012 & -0.010 \\
\hline T-statistics & 1.425 & 1.615 & 1.614 & 2.214 & 2.312 & 0.071 & -0.739 \\
\hline $\operatorname{IWR}(-2)$ & 1.243 & 1.518 & 1.778 & 0.597 & 1.773 & -0.164 & 0.007 \\
\hline T-statistics & 1.936 & 2.136 & 2.278 & 0.713 & 1.753 & -1.006 & 0.505 \\
\hline $\operatorname{IWM}(-1)$ & -1.101 & -1.310 & -1.412 & -1.552 & -2.043 & -0.011 & 0.001 \\
\hline T-statistics & -2.761 & -2.969 & -2.913 & -2.982 & -3.252 & -0.111 & 0.081 \\
\hline IWM(-2) & -0.773 & -0.912 & -0.983 & -0.607 & -1.502 & -0.044 & -0.008 \\
\hline T-statistics & -1.920 & -2.047 & -2.010 & -1.156 & -2.370 & -0.429 & -0.983 \\
\hline EFA(-1) & -0.166 & -0.216 & -0.385 & -0.063 & -0.232 & 0.071 & -0.012 \\
\hline T-statistics & -0.494 & -0.582 & -0.943 & -0.144 & -0.439 & 0.834 & -1.755 \\
\hline $\operatorname{EFA}(-2)$ & -0.087 & 0.061 & 0.116 & -0.052 & -0.120 & -0.065 & 0.003 \\
\hline T-statistics & -0.266 & 0.167 & 0.290 & -0.122 & -0.232 & -0.783 & 0.466 \\
\hline EEM(-1) & -0.087 & -0.101 & -0.220 & 0.040 & -0.090 & 0.028 & 0.008 \\
\hline T-statistics & -0.434 & -0.454 & -0.902 & 0.152 & -0.284 & 0.553 & 1.951 \\
\hline $\operatorname{EEM}(-2)$ & 0.172 & 0.179 & 0.118 & 0.148 & 0.166 & 0.064 & 0.002 \\
\hline T-statistics & 0.840 & 0.792 & 0.475 & 0.554 & 0.516 & 1.232 & 0.534 \\
\hline AGG(-1) & -0.053 & 0.112 & 0.215 & -0.652 & -0.190 & -0.077 & -0.020 \\
\hline T-statistics & -0.096 & 0.183 & 0.318 & -0.898 & -0.217 & -0.543 & -1.812 \\
\hline AGG(-2) & -1.190 & -1.573 & -1.952 & -1.196 & -1.356 & -0.293 & -0.033 \\
\hline T-statistics & -2.158 & -2.577 & -2.912 & -1.662 & -1.561 & -2.088 & -2.953 \\
\hline SHV(-1) & 1.045 & 0.365 & -1.037 & 7.626 & 9.301 & -0.716 & 0.143 \\
\hline T-statistics & 0.181 & 0.057 & -0.147 & 1.010 & 1.021 & -0.487 & 1.230 \\
\hline SHV(-2) & -4.225 & -4.722 & -2.246 & -9.948 & -7.345 & 0.032 & 0.693 \\
\hline T-statistics & -0.752 & -0.760 & -0.329 & -1.357 & -0.830 & 0.022 & 6.144 \\
\hline $\mathrm{C}$ & 0.011 & 0.014 & 0.014 & 0.011 & 0.009 & 0.008 & 0.000 \\
\hline T-statistics & 1.258 & 1.513 & 1.346 & 0.952 & 0.710 & 3.560 & 1.764 \\
\hline $\begin{array}{l}\text { Adj. } \\
\text { R-squared }\end{array}$ & 0.213 & 0.289 & 0.259 & 0.140 & 0.197 & 0.082 & 0.711 \\
\hline S. E. equation & 0.047 & 0.052 & 0.058 & 0.062 & 0.075 & 0.012 & 0.001 \\
\hline F-statistic & 2.315 & 2.979 & 2.694 & 1.789 & 2.194 & 1.433 & 12.955 \\
\hline
\end{tabular}




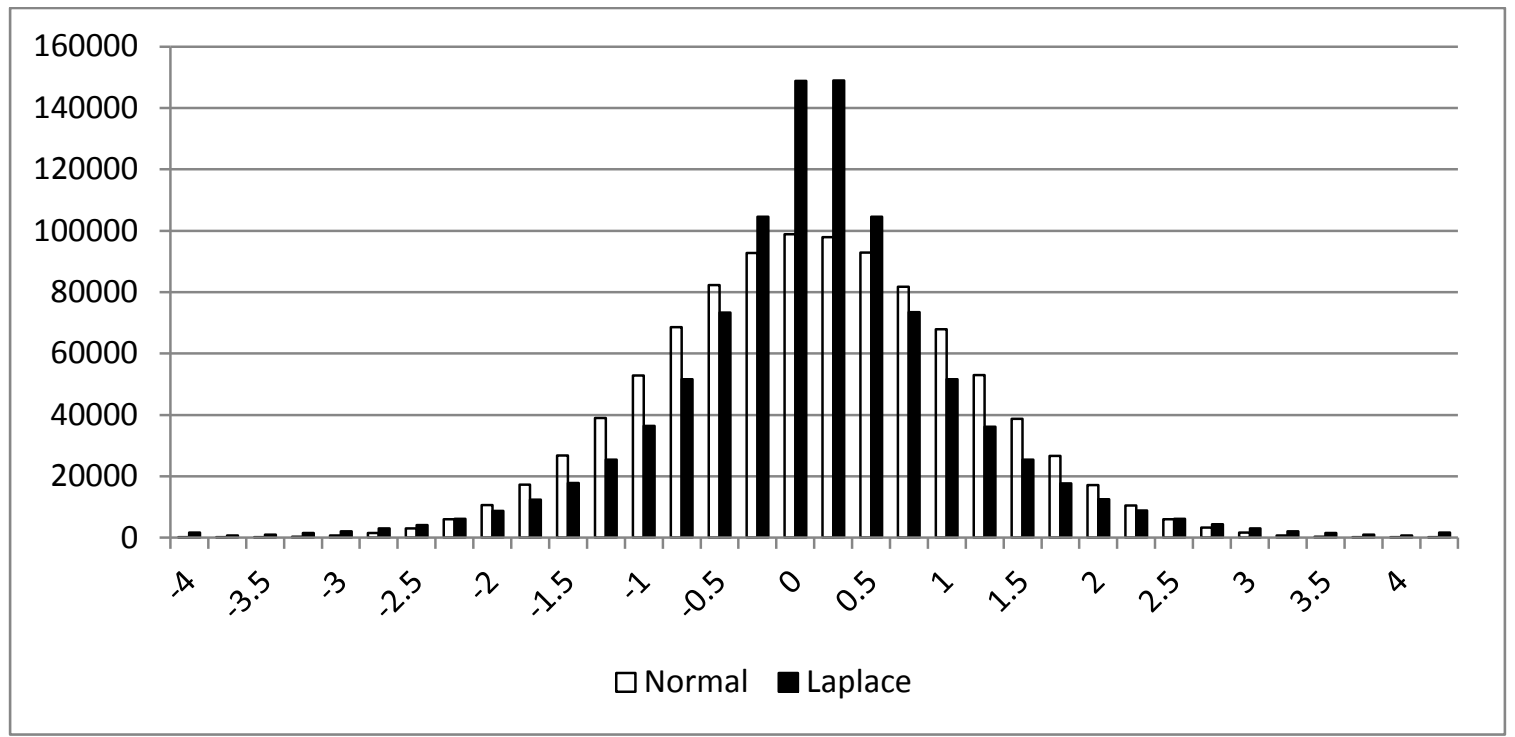

Figure 2: Normal Versus Laplace Distributions With Zero Mean And Standard Deviations Of 1

After this, the U's need to be adjusted to have the standard deviation of the respective standard errors of the estimate from the estimation phase. This process may be denoted by

E_iwb $=$ U_iwb *std_iwb
E_iwr $=$ U_iwr *std_iwr
E_iwm $=$ U_iwm *std_iwm
E_efa $=$ U_efa*std_efa
E_eem $=$ U_eem *std_eem
E_agg $=$ U_agg *std_agg
E_shv $=$ U_shv*std_shv

where

Std_iwb $\quad=0.047324551$

Std_iwr $\quad=0.052377427$

Std_iwm $\quad=0.057510932$

Std_efa $\quad=0.061758574$

Std_eem $\quad=0.074534596$

Std_agg $\quad=0.012039709$

Std_shv $\quad=0.000950352$

At this point, there are 1200 draws of 600 observations for each of the eight error terms that will now be used to generate asset class returns for input into the four alternative TDF portfolios. The functions generating the total returns from each of the asset class (based on Table 1) are denoted below. As seen, the error terms generated above feed into each of the respective portfolios below.

$\operatorname{IWB}=0.752551433504203 * \operatorname{IWB}(-1)-0.802416527959354 * \operatorname{IWB}(-2)+$

$0.973772753402187 * \operatorname{IWR}(-1)+1.24321857778592 * \operatorname{IWR}(-2)-1.10111393585627 * \operatorname{IWM}(-1)-$ $0.772884068643863 * I W M(-2)-0.165934558783426 * E F A(-1) \quad-0.0871653847118238 * E F A(-2) \quad-$ $0.0869991894476129 * \operatorname{EEM}(-1)+0.171582517114739 * \operatorname{EEM}(-2)-0.0531507372690358 * A G G(-1)-$ $1.18993903831459 * A G G(-2)+1.04529243004763 * \operatorname{SHV}(-1)-4.22532351427391 * \operatorname{SHV}(-2)+$ $0.0106455685917119+\mathbf{E} \mathbf{1}$ 


\begin{abstract}
IWR $=0.867848438912276 * I W B(-1)-1.18818329562256 * \operatorname{IWB}(-2)+1.22163538644235 * I W R(-1)+$ $1.51793031738226 * \operatorname{IWR}(-2) \quad-1.31039016378243 * \operatorname{IWM}(-1)-0.911921380942444 * \operatorname{IWM}(-2) \quad-$ $0.216375109122014 * \mathrm{EFA}(-1)+0.0606285810450529 * \mathrm{EFA}(-2)-0.100718094581398 * \mathrm{EEM}(-1)+$ $0.179087818887902 * \operatorname{EEM}(-2)+0.11246452930345{ }^{*} \mathrm{AGG}(-1)-1.57260378292597 * \mathrm{AGG}(-2)+$ $0.364836395036171 * \operatorname{SHV}(-1)-4.72249440551937 * \operatorname{SHV}(-2)+0.0141727185333979+\mathbf{E 2}$

$\mathrm{IWM}=1.17997825033062 * \operatorname{IWB}(-1)-1.3494781199399 * \operatorname{IWB}(-2)+1.3406064143984 * \operatorname{IWR}(-1)+$ $1.77805358140393 * I W R(-2)-1.41196527702567 * \operatorname{IWM}(-1)-0.98298744143937 * I W M(-2) \quad-$ $0.385425549436699 * \mathrm{EFA}(-1)+0.115553859713728 * \mathrm{EFA}(-2)-0.219724157196373 * \mathrm{EEM}(-1)+$ $0.117782822016925 * E E M(-2)+0.214697221581044 * A G G(-1)-1.95167622460152 * A G G(-2)-$ $1.03686244952815 * \operatorname{SHV}(-1)-2.24649866396715 * \operatorname{SHV}(-2)+0.0138422953187277+\mathbf{E 3}$
\end{abstract}

$\mathrm{EFA}=-0.101942700023687 * \operatorname{IWB}(-1)-0.403542834068757 * \operatorname{IWB}(-2)+1.9750715471382 * \operatorname{IWR}(-1)+$ $0.597438640364811 * \operatorname{IWR}(-2)-1.55199835528502 * \operatorname{IWM}(-1)-0.607341414385304 * \operatorname{IWM}(-2) \quad-$ $0.0630379418027255 * \mathrm{EFA}(-1)-0.0522199061136299 * \mathrm{EFA}(-2)+0.0396692730149572 * \mathrm{EEM}(-1)+$ $0.147711685707595 * \operatorname{EEM}(-2) \quad-0.651942731646652 * A G G(-1) \quad-1.19602930242636 * A G G(-2)+$ 7.62603799795967*SHV( - 1) - 9.948322275526746*SHV( - 2) + 0.0105118368973726 +E4

$\mathrm{EEM}=0.23088349797098 * \mathrm{IWB}(-1)-0.657447668257287 * \operatorname{IWB}(-2)+2.48872896288195 * \mathrm{IWR}(-1)+$ $1.7734529989012 * I W R(-2) \quad-2.04265347790957 * \operatorname{IWM}(-1)-1.50239051584133 * \operatorname{IWM}(-2) \quad-$ $0.232196949877142 * \operatorname{EFA}(-1)-0.119963616109168 * \operatorname{EFA}(-2)-0.0895669019001212 * \operatorname{EEM}(-1)+$ $0.165975259095549 * \operatorname{EEM}(-2) \quad-0.190314070154127 * A G G(-1)-1.3557087073975 * A G G(-2)+$ 9.30094482425304*SHV( - 1) - 7.34451860614538*SHV( - 2) + 0.0094696412422332+E5

$\mathrm{AGG}=-0.171694307980117 * \operatorname{IWB}(-1)+0.183959751872677 * \operatorname{IWB}(-2)+0.0122873689066476 * \operatorname{IWR}(-1)-$ $0.164390457697291 * \operatorname{IWR}(-2)-0.0113122506222622 * \operatorname{IWM}(-1)-0.0439715618983832 * \operatorname{IWM}(-2)+$ $0.0713337874222998 * \operatorname{EFA}(-1)-0.0652913556617032 * \mathrm{EFA}(-2)+0.0281890991121137 * \mathrm{EEM}(-1)+$ $0.0640227893347201 * \operatorname{EEM}(-2)-0.0768168036149046 * A G G(-1)-0.292874858872196 * A G G(-2)-$ $0.716134322628459 * \operatorname{SHV}(-1)+0.0318936612200785 * \operatorname{SHV}(-2)+0.00766774896661159+\mathbf{E 6}$

SHV $=0.0102388630016491 * \operatorname{IWB}(-1)-0.0013173803141981 * \operatorname{IWB}(-2)-0.0101379597059312 * \operatorname{IWR}(-1)+$ $0.00651225617759965 * \operatorname{IWR}(-2)+0.00064578717692025 * \operatorname{IWM}(-1)-0.00794309735415262 * \operatorname{IWM}(-2)-$ $0.0118439508000982 * \operatorname{EFA}(-1)+0.0030641495260698 * \operatorname{EFA}(-2)+0.00785491080125396 * \operatorname{EEM}(-1)+$ $0.00219036440686387 * \operatorname{EEM}(-2)-0.0202384322832439 * \mathrm{AGG}(-1)-0.0327044602861317 * \mathrm{AGG}(-2)+$ $0.142958379176249 * \operatorname{SHV}(-1)+0.692893162016182 * \operatorname{SHV}(-2)+0.000299943130797388+\mathbf{E} 7$

The 2000 draws (each of 600 observations) for U_IWB, U_IWR, U_IWM, U_EFA, U_EEM, U_AGG, and U_ SHV are used to generate 2000 draws of 600 observations each of these asset classes per the previous section's methodology. The simulated total returns reflect both month-to-month price changes as well as dividend accumulations. Since the data used to estimate the functions were based on ETFs, the estimations were net of expense rations, and so the simulated results would also be net of expense rations.

The four alternative TDFs, each with a varying degree of equity versus fixed-income securities, ranging from $90 \%$ equity and 10\% fixed income for the TDF 2055 (aggressive) portfolio to $25 \%$ equity and $75 \%$ fixed income for the TDF Retirement Income (conservative) portfolio. Within each equity sleeve, the mix between U.S. large-, and small-cap assets classes and developed country and emerging market countries varies as the risk classification changes across the TDF glide path, and as well as the mix between the two fixed-income asset classes. The weights used in constructing the four portfolios below. 
TDF 2055 (Aggressive)

TDF 2030 (Baseline)

TDF 2015 (Balanced)

TDF Retirement Income (Conservative) =

$$
\begin{array}{ll}
=\quad & 0.30 * \mathrm{IWB}+0.225 * \mathrm{IWR}+0.125 * \mathrm{IWM}+0.125 * \mathrm{EFA} \\
& +0.125 * \mathrm{EEM}+0.10 * \mathrm{AGG}+0.00 * \mathrm{SHV} \\
& 0.25 * \mathrm{IWB}+0.15 * \mathrm{IWR}+0.10 * \mathrm{IWM}+0.10 * \mathrm{EFA} \\
& +0.10 * \mathrm{EEM}+0.30 * \mathrm{AGG}+0.00 * \mathrm{SHV} \\
= & 0.175 * \mathrm{IWB}+0.125 * \mathrm{IWR}+0.10 * \mathrm{IWM}+0.05 * \mathrm{EFA} \\
& +0.05 * \mathrm{EEM}+0.40 * \mathrm{AGG}+0.10 * \mathrm{SHV} \\
= & 0.10 * \mathrm{IWB}+0.075 * \mathrm{IWR}+0.05 * \mathrm{IWM}+0.0125 * \mathrm{EFA} \\
& +0.0125 * \mathrm{EEM}+0.55 * \mathrm{AGG}+0.20 * \mathrm{SHV}
\end{array}
$$

\section{OVERALL COMPARISON OF RESULTS FOR ONE-MONTH RETURNS UNDER THE TWO DISTRIBUTIONS}

Before proceeding with the comparison of cumulative returns over alternative investment horizons for the two distributions, it is useful to compare simple one-month returns of the TDF portfolios with the two distributions in Figure 2 to assess effects of portfolio diversification on the respective distributions. For simplicity, only one of the four TDF portfolios is use, namely the 2055 TDF portfolio which has the aggressive equity holdings. One million one-month growth rates are reported below in Figure 3 for the two distributions.

Interestingly, the tails of the two distributions do not differ as much as reported in Figure 2. Thus, once asset class diversification is introduced, the tail differences between the two distributions is reduced. There is also an effect on the peak of the Laplace versus the normal distribution. The Laplace still have a sharper peak, but asset class diversification has flattened it a bit compared with Figure 2.

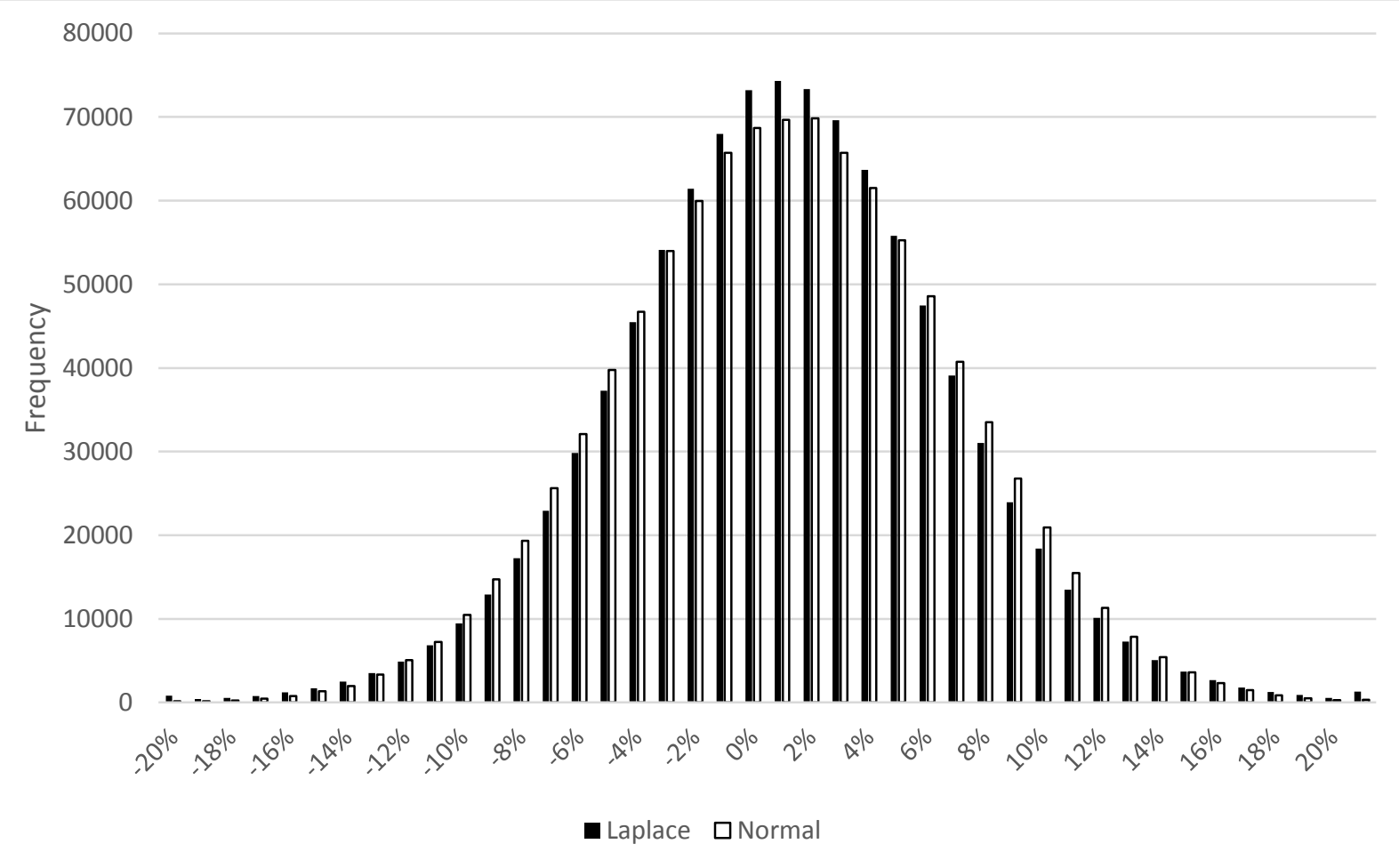

Figure 3: Laplace Versus Normal Distribution Of One-Month Total Returns For The TDF 2055 (Aggressive Portfolio Equity) 


\section{CUMULATIVE RETURNS}

Next, cumulative returns are calculated. To do this, the time path of $\$ 100$ invested 50 years ago, e.g. on December 1963 through December 2013, is calculated using the simulated monthly returns for each of the four portfolios across 2000 draws of the 600 observations per draw. This may be de denoted by:

portfolio value $i_{i, t}=$ portfolio value $i, t-1=\left(1+1+\right.$ return $\left._{i, t}\right)$

Where $\quad \mathrm{I}=1,2,3,4$ and represents the four asset portfolios

And $\quad \mathrm{t} \quad=\quad 0, \ldots, 500$ and represents the 500 draws for a working lifetime.

This process is repeated for each of the 2000 draws.

Finally, compound annual returns are calculated over each of the 2,000 TDF portfolios for both distributions over successive (non-overlapping) 1-, 2-, 3-, and 5-year, 5-year horizons. Before proceeding with the detailed comparison across alternative investment horizons, one-year total returns are reported in Figure 4 for the 2055 TDF (aggressive equity portfolio).

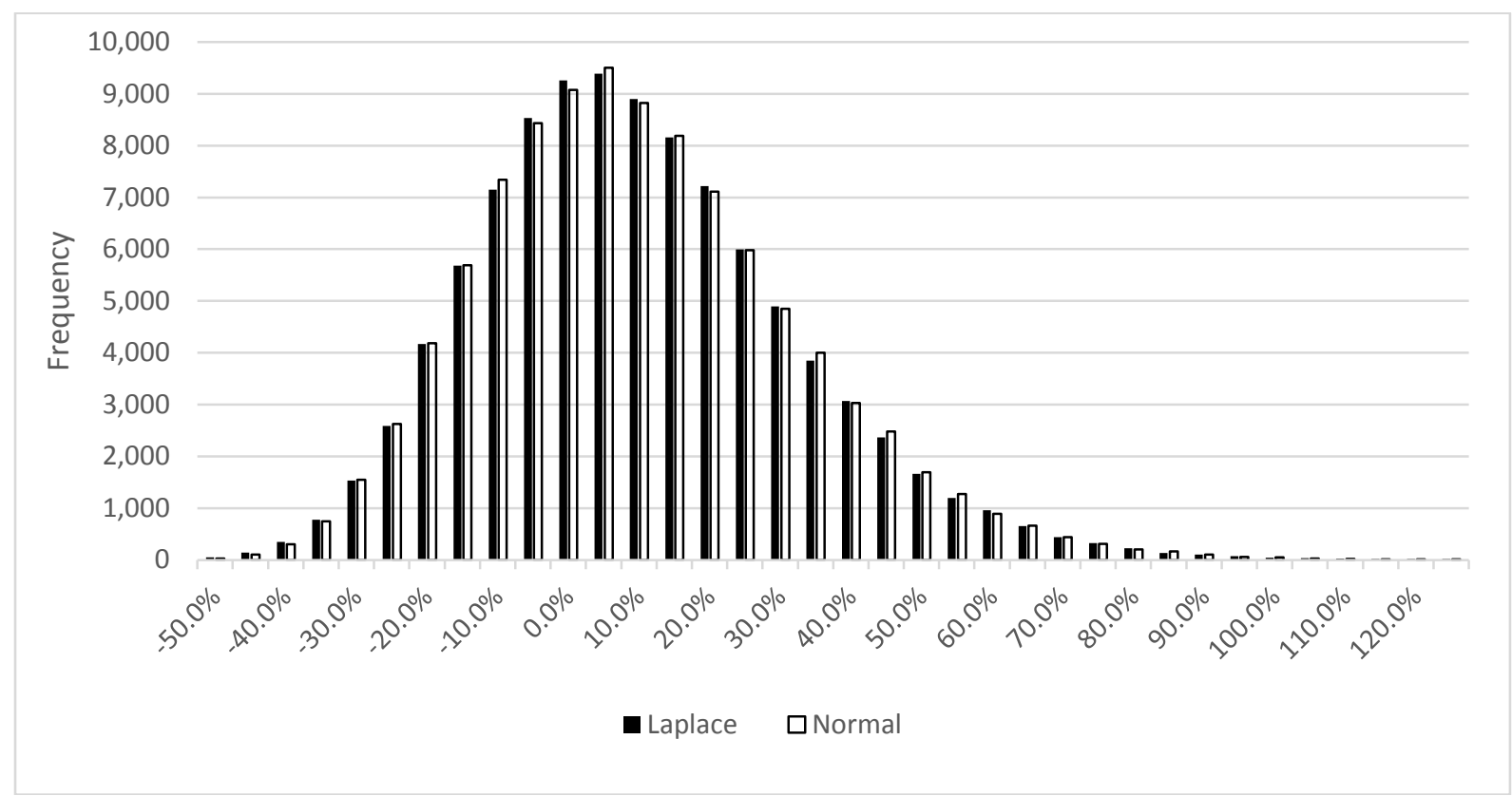

Figure 4: Laplace versus Normal Distribution of Cumulative

One-Year Total Returns for the TDF 2055 (Aggressive Portfolio Equity

Once cumulative returns are calculated, it appears that the two distribution produce results that are qualitatively indistinguishable. Tails are quite similar as are the two peaks. Additionally, calculation of cumulative returns introduces a skewed distribution toward positive results for both distribution.

Next, summary measures (average compound annual return, standard deviations of each of the compound annual returns, lowest and highest of the cumulative returns for each horizon for the Laplace and normal distribution are calculated. Also, the percent of negative compound annual returns over each of the horizons as well as the average negative returns over each of the horizons are calculated. Results for these summary measures are reported in Tables 3 and 4 for the Laplace and the normal distributions, respectively. 


\section{PRELIMINARY FINDINGS}

As can be seen, there are a total of 100,000 one-year compound annual returns computed from the nonoverlapping investment horizons over the 50-year working life and the 2000 draws for each risk-based portfolio $(2,000 * 600 / 12)$. Next, there are 50,000 two-year, non-overlapping, horizons $(2000 * 600 / 24), 32,000$, three-year nonoverlapping horizons, and 20,000 five-year non-overlapping horizons.

In comparing Tables 3 and 4 and looking across the four risk-based portfolios, the various summary dispersion measures showed little difference between the Laplace and the normal distributions. Roughly half the time, the Laplace distribution has wider dispersion measures (standard deviations, lowest and highest compound annual returns) than the normal distribution and vice versa. Similarly roughly half the time, the percent of negative returns as well as the average negative returns are roughly half and half between the two distributions. Interestingly, effects of differences in outliers between the two distributions are apparently mitigated when compound annual returns over alternative non-overlapping investment horizons.

Thus, the role of long-tail distributions is not as dramatic as some may have felt in the aftermath of the crisis, Rather, as will be seen in the next section, the likelihood of "bad things happening" is simply very high, over 1-year and 2-year investment horizons under either distribution, and in the search for an explanation, effects of longtail distributions dominated the media discussion.

Given the similarity of results, discussion will now focus only on the results reported in Table 3 for the Laplace distribution. In looking across the four alternative risk-based portfolios, the standard deviations of the compound annual returns are positively related to the relative share of equity in the portfolio. Similarly, the magnitude as well as the range between the highest and the lowest total returns in each of the investment horizons is related to the share of equity in the portfolio. Interestingly, in all but a few cases, the high and the low total returns are outside the three standard deviation mark, this confirming the presence of long-tail characteristics that the study sought to produce.

\section{PORTFOLIO RISK AND PROSPECTS FOR NEGATIVE RETURNS}

In examining the 1-, 2-, 3-, and 5-year investment horizons, negative compound annual returns are possible over each of these horizons for all four risk based portfolios and under both distributions. Thus, there is a strong possibility of an unpleasant outcome as an individual approaches retirement, or even during retirement, simply from the randomness of life. Interestingly, readers should note, however, in a world of symmetrical distributions, there is also the chance of very large positive outcomes in each of the portfolios over each of the investment horizons. Thus, the randomness of life could provide everything from a very positive outcome to a negative outcome in the years leading up to retirement and during retirement.

For example, simulations for the TDF 2055 portfolio produce negative 1- and 2-year compound annual returns (CAR) around $40 \%$ of the time. That is, roughly $2 / 5$ of the time, this aggressive portfolio would produce negative CARs over relatively short investment horizons. From Table 3, one can see that the negative CARs average roughly $-13 \%$ for both the 1- and 2-year horizons. The largest negative CAR is around $62 \%$ for both the 1- and 2year horizons. Chances of negative returns fell in the 3 - and the 5-year investment horizons. CARs calculated from the portfolio simulations produce negative returns $28 \%$ of the time for the 5 -year horizon with negative compound returns averaging $-5.4 \%$

Likelihood of negative CARs falls as the equity allocation is reduced. For TDF 2030 portfolios (75/25 split), negative CARs over the 1- and 2-year investment horizons occurred roughly $37 \%$ of the time and averaged roughly $-10 \%$. Safety continued to improve with the 50/50 split in the TDF 2015 portfolios with negative CARs over the 1- and 2-year investment horizons experience roughly around $31 \%$ of the time with the negative CARs averaging around $-6.87 \%$

The conservative portfolio (TDF Retirement Income portfolio) provides the most protection against a "bad" outcome (aka, black swan event). As expected, it has a lower realized simulated return compared with the other 
portfolios. For example, its simulated 1-year compound annual return averaged 5.1\% versus $7.4 \%$ for the TDF 2055 portfolios. Interestingly, while there is a give-up in return, it is not high once longer horizons are considered. For example, when looking at the simulated 5-year compound annual returns, returns are quite close ranging from 5.1\% for the Retirement Income fund to 5.6\% for the TDF 2030 portfolios.

Nonetheless, there is still the possibility of negative returns for the TDF Retirement Income portfolios. The simulations produced negative 1- and 2- year compound annual returns about $18 \%$ of the time which averaged $2.7 \%$. Even the simulations over a 5 -year investment horizon produced negative returns $1.2 \%$ of the time averaging $-0.8 \%$

\section{“TO” VERSUS “THROUGH” TDFS}

The analysis in the previous sections used matched the definition of asset mix in the TDF portfolios to the equity / fixed-income mix in Table 1 which "blends" the equity/bond mix for the "to" and "through" funds. If one were to look at the equity/bond mix for TDFs in Figure 1, the 50/50 split is a bit more conservative than the 55/45 split in the "through" TDFs. Yet this produced negative returns over 1- and 2-year horizons roughly one-third of the time.

\section{VOLATILITY}

Some may question whether the regression standard errors reported in Table 1 and used in the simulations fully capture the jump in volatility observed during the crisis. Since the largest negative returns were experienced in 2008 and 2009, it seems safe to conclude that the estimation results do capture the volatility of the crisis. 
Table 3: Simulated Returns for Four Target Date Funds using the Laplace Distribution

\begin{tabular}{|c|c|c|c|c|c|c|c|}
\hline \multicolumn{8}{|c|}{ Target Date 2055 Fund (90 percent equity) } \\
\hline $\begin{array}{l}\text { Length of Successive } \\
\text { Investment Horizons }\end{array}$ & $\begin{array}{l}\text { Number of Successive } \\
\text { Non-overlapping } \\
\text { Investment Horizons }\end{array}$ & $\begin{array}{c}\text { Average Compound } \\
\text { Annual Investment } \\
\text { Horizons Returns } \\
\end{array}$ & $\begin{array}{c}\text { Standard Deviation of } \\
\text { the Investment Horizon } \\
\text { Returns }\end{array}$ & $\begin{array}{l}\text { Lowest Investment } \\
\text { Horizon Return }\end{array}$ & $\begin{array}{l}\text { Highest Investment } \\
\text { Horizon Return }\end{array}$ & $\begin{array}{c}\% \text { Negative Investment } \\
\text { Horizons Returns }\end{array}$ & $\begin{array}{c}\text { Average Negative } \\
\text { Investment Horizons } \\
\text { Returns } \\
\end{array}$ \\
\hline 1-Year & 100,000 & $7.365 \%$ & $22.593 \%$ & $-62.021 \%$ & $143.433 \%$ & $40.232 \%$ & $-13.428 \%$ \\
\hline 2-Year & 50,000 & $6.800 \%$ & $22.244 \%$ & $-62.021 \%$ & $136.737 \%$ & $41.186 \%$ & $-13.232 \%$ \\
\hline 3-Year & 32,000 & $5.838 \%$ & $12.236 \%$ & $-35.377 \%$ & $75.017 \%$ & $33.059 \%$ & $-7.201 \%$ \\
\hline 5-Year & 20,000 & $5.564 \%$ & $9.319 \%$ & $-25.881 \%$ & $48.776 \%$ & $28.275 \%$ & $-5.370 \%$ \\
\hline \multicolumn{8}{|c|}{ Target Date 2030 Fund (75 percent equity) } \\
\hline $\begin{array}{l}\text { Length of Successive } \\
\text { Investment Horizons }\end{array}$ & $\begin{array}{l}\text { Number of Successive } \\
\text { Non-overlapping } \\
\text { Investment Horizons }\end{array}$ & $\begin{array}{c}\text { Average Compound } \\
\text { Annual Investment } \\
\text { Horizons Returns } \\
\end{array}$ & $\begin{array}{c}\text { Standard Deviation of } \\
\text { the Investment Horizon } \\
\text { Returns }\end{array}$ & $\begin{array}{l}\text { Lowest Investment } \\
\text { Horizon Return }\end{array}$ & $\begin{array}{l}\text { Highest Investment } \\
\text { Horizon Return }\end{array}$ & $\begin{array}{c}\% \text { Negative Investment } \\
\text { Horizons Returns }\end{array}$ & $\begin{array}{c}\text { Average Negative } \\
\text { Investment Horizons } \\
\text { Returns } \\
\end{array}$ \\
\hline $1-$ Year & 100,000 & $6.783 \%$ & $17.055 \%$ & $-50.852 \%$ & $101.641 \%$ & $36.629 \%$ & $-10.065 \%$ \\
\hline 2-Year & 50,000 & $6.351 \%$ & $16.813 \%$ & $-50.852 \%$ & $96.953 \%$ & $37.556 \%$ & $-9.897 \%$ \\
\hline 3-Year & 32,000 & $5.943 \%$ & $9.297 \%$ & $-26.695 \%$ & $55.739 \%$ & $26.759 \%$ & $-5.169 \%$ \\
\hline 5-Year & 20,000 & $5.787 \%$ & $7.090 \%$ & $-18.678 \%$ & $37.724 \%$ & $21.050 \%$ & $-3.572 \%$ \\
\hline \multicolumn{8}{|c|}{ Target Date 2015 Fund (50\% equity) } \\
\hline $\begin{array}{l}\text { Length of Successive } \\
\text { Investment Horizons }\end{array}$ & $\begin{array}{l}\text { Number of Successive } \\
\text { Non-overlapping } \\
\text { Investment Horizons }\end{array}$ & $\begin{array}{c}\text { Average Compound } \\
\text { Annual Investment } \\
\text { Horizons Returns } \\
\end{array}$ & $\begin{array}{c}\text { Standard Deviation of } \\
\text { the Investment Horizon } \\
\text { Returns }\end{array}$ & $\begin{array}{l}\text { Lowest Investment } \\
\text { Horizon Return }\end{array}$ & $\begin{array}{l}\text { Highest Investment } \\
\text { Horizon Return }\end{array}$ & $\begin{array}{c}\% \text { Negative Investment } \\
\text { Horizons Returns }\end{array}$ & $\begin{array}{c}\text { Average Negative } \\
\text { Investment Horizons } \\
\text { Returns }\end{array}$ \\
\hline 1-Year & 100,000 & $6.071 \%$ & $11.807 \%$ & $-37.708 \%$ & $66.560 \%$ & $31.428 \%$ & $-6.802 \%$ \\
\hline 2-Year & 50,000 & $5.749 \%$ & $11.658 \%$ & $-37.708 \%$ & $65.029 \%$ & $32.254 \%$ & $-6.695 \%$ \\
\hline 3-Year & 32,000 & $5.712 \%$ & $6.473 \%$ & $-18.098 \%$ & $38.458 \%$ & $18.791 \%$ & $-3.331 \%$ \\
\hline 5-Year & 20,000 & $5.639 \%$ & $4.947 \%$ & $-11.934 \%$ & $27.343 \%$ & $12.895 \%$ & $-2.828 \%$ \\
\hline \multicolumn{8}{|c|}{ Target Date Retirement Income Fund (25\% equity) } \\
\hline $\begin{array}{l}\text { Length of Successive } \\
\text { Investment Horizons }\end{array}$ & $\begin{array}{l}\text { Number of Successive } \\
\text { Non-overlapping } \\
\text { Investment Horizons }\end{array}$ & $\begin{array}{l}\text { Average Compound } \\
\text { Annual Investment } \\
\text { Horizons Returns }\end{array}$ & $\begin{array}{l}\text { Standard Deviation of } \\
\text { the Investment Horizon } \\
\text { Returns }\end{array}$ & $\begin{array}{l}\text { Lowest Investment } \\
\text { Horizon Return }\end{array}$ & $\begin{array}{l}\text { Highest Investment } \\
\text { Horizon Return }\end{array}$ & $\begin{array}{c}\% \text { Negative Investment } \\
\text { Horizons Returns }\end{array}$ & $\begin{array}{c}\text { Average Negative } \\
\text { Investment Horizons } \\
\text { Returns }\end{array}$ \\
\hline 1-Year & 100,000 & $5.114 \%$ & $5.562 \%$ & $-17.837 \%$ & $31.663 \%$ & $17.780 \%$ & $-2.803 \%$ \\
\hline 2-Year & 50,000 & $4.948 \%$ & $5.520 \%$ & $-17.231 \%$ & $31.004 \%$ & $18.364 \%$ & $-2.749 \%$ \\
\hline 3-Year & 32,000 & $5.098 \%$ & $3.038 \%$ & $-6.835 \%$ & $19.019 \%$ & $4.434 \%$ & $-1.185 \%$ \\
\hline 5 -Year & 20,000 & $5.084 \%$ & $2.321 \%$ & $-3.411 \%$ & $14.862 \%$ & $1.230 \%$ & $-0.821 \%$ \\
\hline \multicolumn{8}{|c|}{ Table 4: Simulated Returns for Four Target Date Funds using the Normal Distribution } \\
\hline \multicolumn{8}{|c|}{ Target Date 2055 Fund (Aggressive Fund) } \\
\hline $\begin{array}{l}\text { Length of Successive } \\
\text { Investment Horizons }\end{array}$ & $\begin{array}{l}\text { Number of Successive } \\
\text { Non-overlapping } \\
\text { Investment Horizons }\end{array}$ & $\begin{array}{c}\text { Average Compound } \\
\text { Annual Investment } \\
\text { Horizons Returns }\end{array}$ & $\begin{array}{c}\text { Standard Deviation of } \\
\text { the Investment Horizon } \\
\text { Returns }\end{array}$ & $\begin{array}{c}\text { Lowest Investment } \\
\text { Horizon Return }\end{array}$ & $\begin{array}{c}\text { Highest Investment } \\
\text { Horizon Return }\end{array}$ & $\begin{array}{c}\% \text { Negative Investment } \\
\text { Horizons Returns }\end{array}$ & $\begin{array}{c}\text { Average Negative } \\
\text { Investment Horizons } \\
\text { Returns }\end{array}$ \\
\hline 1-Year & 100,000 & $7.431 \%$ & $22.504 \%$ & $-59.378 \%$ & $160.050 \%$ & $40.082 \%$ & $-13.398 \%$ \\
\hline 2-Year & 50,000 & $6.888 \%$ & $22.045 \%$ & $-58.308 \%$ & $160.050 \%$ & $40.542 \%$ & $-13.234 \%$ \\
\hline 3-Year & 32,000 & $5.909 \%$ & $12.185 \%$ & $-33.371 \%$ & $62.414 \%$ & $32.984 \%$ & $-7.143 \%$ \\
\hline 5-Year & 20,000 & $5.625 \%$ & $9.236 \%$ & $-28.307 \%$ & $49.364 \%$ & $27.930 \%$ & $-5.238 \%$ \\
\hline
\end{tabular}


(Table 3 continued)

Target Date 2030 Fund

\begin{tabular}{|c|c|c|c|c|c|c|c|}
\hline $\begin{array}{l}\text { Length of Successive } \\
\text { Investment Horizons }\end{array}$ & $\begin{array}{l}\text { Number of Successive } \\
\text { Non-overlapping } \\
\text { Investment Horizons }\end{array}$ & $\begin{array}{c}\text { Average Compound } \\
\text { Annual Investment } \\
\text { Horizons Returns }\end{array}$ & $\begin{array}{c}\text { Standard Deviation of } \\
\text { the Investment Horizon } \\
\text { Returns }\end{array}$ & $\begin{array}{l}\text { Lowest Investment } \\
\text { Horizon Return }\end{array}$ & $\begin{array}{l}\text { Highest Investment } \\
\text { Horizon Return }\end{array}$ & $\begin{array}{l}\% \text { Negative Investment } \\
\text { Horizons Returns }\end{array}$ & $\begin{array}{c}\text { Average Negative } \\
\text { Investment Horizons } \\
\text { Returns }\end{array}$ \\
\hline 1-Year & 100,000 & $6.832 \%$ & $16.988 \%$ & $-48.646 \%$ & $109.821 \%$ & $36.508 \%$ & $-10.038 \%$ \\
\hline 2-Year & 50,000 & $6.417 \%$ & $16.664 \%$ & $-48.085 \%$ & $109.821 \%$ & $36.880 \%$ & $-9.934 \%$ \\
\hline 3-Year & 32,000 & $5.993 \%$ & $9.258 \%$ & $-25.098 \%$ & $47.041 \%$ & $26.803 \%$ & $-5.114 \%$ \\
\hline 5-Year & 20,000 & $5.830 \%$ & $7.027 \%$ & $-20.970 \%$ & $38.034 \%$ & $20.650 \%$ & $-3.653 \%$ \\
\hline \multicolumn{8}{|c|}{ Target Date 2015 Fund (Balanced Fund) } \\
\hline $\begin{array}{c}\text { Length of } \\
\text { Successive } \\
\text { Investment Horizons }\end{array}$ & $\begin{array}{l}\text { Number of Successive } \\
\text { Non-overlapping } \\
\text { Investment Horizons }\end{array}$ & $\begin{array}{c}\text { Average Compound } \\
\text { Annual Investment } \\
\text { Horizons Returns }\end{array}$ & $\begin{array}{c}\text { Standard Deviation of } \\
\text { the Investment } \\
\text { Horizon Returns }\end{array}$ & $\begin{array}{l}\text { Lowest Investment } \\
\text { Horizon Return }\end{array}$ & $\begin{array}{l}\text { Highest Investment } \\
\text { Horizon Return }\end{array}$ & $\begin{array}{c}\% \text { Negative } \\
\text { Investment Horizons } \\
\text { Returns }\end{array}$ & $\begin{array}{c}\text { Average Negative } \\
\text { Investment Horizons } \\
\text { Returns }\end{array}$ \\
\hline 1-Year & 100,000 & $6.104 \%$ & $11.756 \%$ & $-35.827 \%$ & $69.356 \%$ & $31.463 \%$ & $-6.749 \%$ \\
\hline 2-Year & 50,000 & $5.794 \%$ & $11.553 \%$ & $-35.827 \%$ & $69.356 \%$ & $31.908 \%$ & $-6.674 \%$ \\
\hline 3-Year & 32,000 & $5.744 \%$ & $6.444 \%$ & $-16.149 \%$ & $33.376 \%$ & $18.875 \%$ & $-3.268 \%$ \\
\hline 5-Year & 20,000 & $5.667 \%$ & $4.903 \%$ & $-13.631 \%$ & $27.259 \%$ & $12.350 \%$ & $-2.240 \%$ \\
\hline \multicolumn{8}{|c|}{ Target Date Retirement Income Fund (Conservative Fund) } \\
\hline Length of Successive & $\begin{array}{l}\text { Number of Successive } \\
\text { Non-overlapping }\end{array}$ & $\begin{array}{l}\text { Average Compound } \\
\text { Annual Investment }\end{array}$ & $\begin{array}{l}\text { Standard Deviation of } \\
\text { the Investment Horizon }\end{array}$ & Lowest Investment & Highest Investment & $\%$ Negative Investment & $\begin{array}{c}\text { Average Negative } \\
\text { Investment Horizons }\end{array}$ \\
\hline Investment Horizons & Investment Horizons & Horizons Returns & Returns & Horizon Return & Horizon Return & Horizons Returns & Returns \\
\hline 1-Year & 100,000 & $5.124 \%$ & $5.538 \%$ & $-17.478 \%$ & $30.274 \%$ & $17.898 \%$ & $-2.742 \%$ \\
\hline 2-Year & 50,000 & $4.960 \%$ & $5.472 \%$ & $-17.478 \%$ & $33.803 \%$ & $18.760 \%$ & $-2.708 \%$ \\
\hline 3-Year & 32,000 & $5.107 \%$ & $3.021 \%$ & $-5.491 \%$ & $17.478 \%$ & $4.334 \%$ & $-1.167 \%$ \\
\hline 5 -Year & 20,000 & $5.091 \%$ & $2.302 \%$ & $-4.009 \%$ & $14.498 \%$ & $1.200 \%$ & $-0.714 \%$ \\
\hline
\end{tabular}




\section{SOCIAL SECURITY AND TDFS ASSET ALLOCATIONS}

Recently, John Bogle - founder of Vanguard - made the argument (Phillips) that target date funds may have too heavy an allocation to bonds for any given target date. This is due to the "fixed income" cash-flow characteristics of social security benefit. He maintains that this criticism is particularly important when the individual retires. With too heavy an allocation to bonds, the appreciation potential of the equity component is reduced.

At the same time, however, results here suggest that implicit "all-in" fixed income component when social security is included provides an important backstop to black swan events. This backstop is more important, the lower is the asset base of the individual relative to social security. In other words, while there may be an over allocation to fix income securities when social security is included, the inclusion of social security is an important risk reduce when black swan even are considered. The importance of social security a backstop increases for those invested in a "though" retirement TDF in their retirement years, given the heavier (riskier) allocation to equities.

\section{CONCLUDING COMMENTS}

Several key findings stemmed from this study. First, once asset diversification and cumulative compound annual growth rates over an investment horizon of a year or longer are considered, the adverse effects of long-tail distributions loose much of their troubling characteristics. The Laplace and the normal distributions give roughly equal results in terms of risk parameters and other measures used in this study. Second, there is no "silver bullet" to protect investors as they approach retirement (or during retirement) from the randomness of a bad event under either the normal or the long-tail (Laplace) distribution. This suggest that a large pool or retirement savings is necessary to weather the consequences of a bad event. Third, social security plays a key role in mitigating effects of bad event, and the role is more important, the smaller is the individual's pool of saving at and during retirement. Finally, TDF whose allocations goes "through retirement" are risker to a bad event than the "to retirement," and because if this, social security's risk mitigating role is more important.

\section{AUTHORS' INFORMATION}

Albert E. DePrince, Jr., Ph.D., Contact Information: albert.deprince@ mtsu.edu, 615-584-1183, Professor, Department of Economics and Finance, Middle Tennessee State University since 1991, in Murfreesboro, TN USA

A. Eugene DePrince III, Ph.D., Contact Information: deprince@ chem.fsu.edu, 865-414-4818, Assistant Professor, Department of Chemistry and Biochemistry, Florida State University since 2013

\section{REFERENCES}

1. John C. Bogle. 2007. "Black Monday and Black Swans.” Risk Management Association. Boca Raton, FL. October 11.

2. Michael J. Brien, Michael, j., Philip J. Cross, Thomas A. Dunn, Joice A. Pharris, and Constantijn W.A. Panis 2010. Target Date Funds and Retirement Savings. Deloitte Financial Advisory Services LLP and Advanced Analytical Consulting Group, Inc. March.

3. DePrince, Albert E., and Pamela D. Morris. 2010. Assessing Alternative Fixed-Weight Asset Allocation Rules. Academy of Finance. Annual Meeting, Chicago, IL, March 24-26.

4. Eisenbrey, Ross. 2008. Testimony before the Subcommittee on Select Revenue Measures of the House Committee on Ways and Means. June 26. http://www.epi.org/publications/entry/webfeatures_testimony_waymeans_20080626/. (Note this testimony was given for Teresa Ghilarducci who was not available on the stated date)

5. $\quad$ Fleck, Carol. 2013. "Beefed-Up Protections May Be Coming for Target Date Funds." June 24. Retrieved from http://blog.aarp.org/2013/06/24/beefed-up-protections-may-be-coming-for-target-date-funds/

6. Gandel, Stephen. 2009. "Why It's Time to Retire the 401(k)." Time. October 19. pp. 28-33. 
7. Green, Bud. 2009. Special Commentary for Plan Sponsors Regarding Target Date Funds, MJM401k. Second Quarter. Retrieved from http://www.mjm401k.com/publications/target_date_funds_white_paper.pdf

8. Hersch, Warren. 2013. EBRI: Nearly three quarters of 401(k) plans include target date funds. LifeHealthPro. January 28. Retrieved from http://www.lifehealthpro.com/2013/01/28/ebri-nearly-threequarters-of-401k-plans-include-t

9. Holden, Srah, John Sabelhaus, and Brian Reid. 2010. Investor Attitudes and Actions. Investment Company Institute. January.

10. Holmer, Martin R. 2009a. Estimating the Accumulation Risks of Life-Cycle Funds. Policy Simulation Group Working Paper.

11. Huberman, Gur, and Wei Jiang. "Offering vs. Choice in 401(k) Plans: Equity Exposure and Number of Funds.” Finance and Economics Division, Columbia Business School.

12. Hunnicutt, Trevor. 2013. "U.S. target-date fund assets hit \$503 bln in 2012." June 18. Retrueved from http://www.reuters.com/article/2013/06/18/retirement-funds-targetdate-idUSL2NOEQ1RS20130618

13. Morningstar. 2013. Morningstar Fund Research Target-Date Series Research Paper 2013 Survey. Retrieved from http://corporate.morningstar.com/us/documents/ResearchPapers/2013TargetDate.pdf

14. Murphy, Phil, and Peter Scraturro. 2012. S\&P Target Date Score Card, Year End 2012. Retrieved from http://www.thecfdd.com/files/tdfbenchmarks/targetdatescorecard-yearend-2012.pdf

15. Pethokoukis, James. 2008. “Would Obama, Dems Kill 401(k) Plans?” Capital Commerce (usnews.com). October 28.

16. Pang, Gaobo and Mark Warshawsky 2009.Asset Allocations and Risk-Return Tradeoffs of Target-Date Funds. Watson Wyatt Worldwide. Working Paper. June 18. Retrieved from http://www.dol.gov/ebsa/pdf/PangWarshawsky061809.pdf

17. Phillips, Don. 2013. "Bogle: Target Date Funds a Bit Too Clever.) Interview with John Bogle. Retrieved from http://www.morningstar.com/cover/videocenter.aspx?id=301426

18. Poterba, James, Joshua Rauh, Steven Venti, and David Wise. 2005. Lifecycle Asset Allocation Strategies and the Distribution of 401(k) Retirement Wealth. NBER Working Paper No. 11974.

19. Regnier, Pat. 2008. "The plan to save early retirement." Money Magazine, April 23. Retrieved from http://money.cnn.com/2008/04/22/pf/retirement/early_retirement.moneymag/

20. S\&P Dow Jones Indicies. 2012. S\&P Target Index Series, Strategy Indexes. Retrieved from http://www.google.com/url?sa=t\&rct=j\&q=\&esrc=s\&source=web\&cd=1\&ved=0CCcQFjAA\&url=http\%3

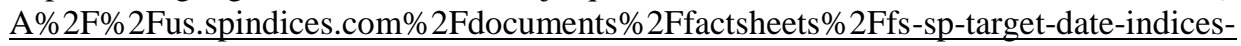
ltr.pdf\%3Fforce_download\%3Dtrue\&ei=5dDqUo3fHunjsASAjYLwBw\&usg=AFQjCNHpuaZmI2aoZ45M suwuI9cuTjGy-A\&sig2=FCEMbc-smdI5gF72LbvDPQ

21. Schurenberg, Eric. 2009. “The 401(k) Has Failed. Let's Admit It.” CBS MoneyWatch.com, June 24.

22. Taleb, Nassim. 2008. "Comments Following Prepared Remarks.” Independent Directors Council. Annual Meeting. November 13.

23. Taylor, John B., and John C. William. “A Black Swan in the Money Market.” Federal Reserve Bank of San Francisco, Working Paper Series, Working Paper 2008-04

24. Zhou, Guofu, and Yingzi Zhu. 2009. "Why Is the Recent Financial Crisis a "Once-in-a-century" Event?" Retrieved from http://ssrn.com/abstract $=1462790$. August. 